\title{
Relationship Between Bleeding Time And Clotting Time Among Gender Difference And Varying Blood Groups In UG Medical Students
}

\author{
Dr. Sasekala.M ${ }^{1}$, Dr.P.Saikumar ${ }^{2}$ \\ '(Post Graduate, Department of Physiology, Bharath University, INDIA) \\ 2 (Professor \& HOD, Department of Physiology, Bharath University, INDIA)
}

\begin{abstract}
Blood group plays a vital role in the field of medicine. There is a clear association between $A B O$ blood group status and von Willebrand factor. Deficiency of $v W F$ leads to Hemorrhagic disorders, while elevated levels are a risk factor for thrombosis. Earlier studies state that the $O$ group individuals have prolonged bleeding time and clotting time. The objective of this study was to assess the relationship between Bleeding time and clotting time among various Blood groups and also to identify any gender difference among the same. This is a cross sectional study including 100 Undergraduate students of age group 17 to 20 years.Bleeding time (by Duke's filter paper method) and Clotting time (by Wright's capillary tube method) was determined after obtaining an informed consent from the students.In our study, bleeding time was prolonged among B group and clotting time was prolonged among AB group, also prolonged bleeding time and clotting time among the females compared to the males.. Our study reveals that $O$ group individuals also share the risk of thrombosis.A larger study group has to be involved for further study and also the plasma von Willebrand factor levels should be estimated to rule out any possible reason.
\end{abstract}

Key words:Bleeding time, Blood groups, clotting time, von Willebrand's factor.

\section{Introduction:}

In the year 1900 scientist Karl Landsteiner identified the $\mathrm{ABO}$ system of blood group which was the starting of Blood banking and Transfusion medicine. The ABO system consists of complex carbohydrate molecules. The A and B Glycosyltransferase encoded by A and B alleles converts H antigen into A and B determinants. This transferase enzyme is deficient in the group $\mathrm{O}$ individuals who continue to express $\mathrm{H}$ antigen (1).Many diseases are found to be associated with Blood groups for eg.Duodenal Ulcer, Diabetes Mellitus, Urinary tract infection, feto- maternal incompatibility etc. (2, 3, and 4).

According to Mourner AE et al.and Qureshi MA et al., there is a clear association between ABO blood group status and Von Willibrand factor $(5,6)$. Von Willebrand factor is a large glycoprotein produced by endothelial cells and megakaryocyte. Its major function is Hemostasis. Deficiency of vWF leads to Hemorrhagic disorders, while elevated levels are a risk factor for thrombosis $(7,8,9)$.As per the study conducted by Gill JC et al (10), Group $\mathrm{O}$ individuals had lowest plasmavWF levels and non $\mathrm{O}$ groups ( A,B and AB) had elevated levels of plasma vWF. They state that there is increased thrombotic risk among the non $\mathrm{O}$ group individuals. This refers to increased Bleeding time and Clotting time among $\mathrm{O}$ group compared to the non $\mathrm{O}$ group individuals. At the same time Daniel $\mathrm{M}$ et al in his study, could not find any association between ABO group and von willebrand factor (11). The objective of this study was to assess the relationship between Bleeding time and clotting time among various Blood groups and also to identify any gender difference among the same.

\section{Material And Methods:}

This study was done among the first year UG students in the department of Physiology of Sree Balaji medical college and Hospital, Chrompet, Chennai.100 undergraduate students within the age group of 17 to 20 years were included in this study. The exclusion criteria for selection of the students were any history of bleeding disordersand h/o drug intake (NSAIDS). Institutional ethical committee clearancewas obtained. Data was collected in respect to the age, sex, height, weight etc. after obtaining informed consent.

Procedures done:Blood group determination was done by adding antisera A and B with the blood sample and confirmation was done by the appearance of clumping among RBCs. Estimation of clotting time was done by Wright's Capillary tube method (12) and bleeding time by Duke's filter paper method.

\section{Results:}

The data of 100 students were collected and analyzed statistically. The study group's age was homogenous (17 to 19 years) as everyone belonged to First year MBBS. Out of 100 students there were fifty four females and forty six males. 


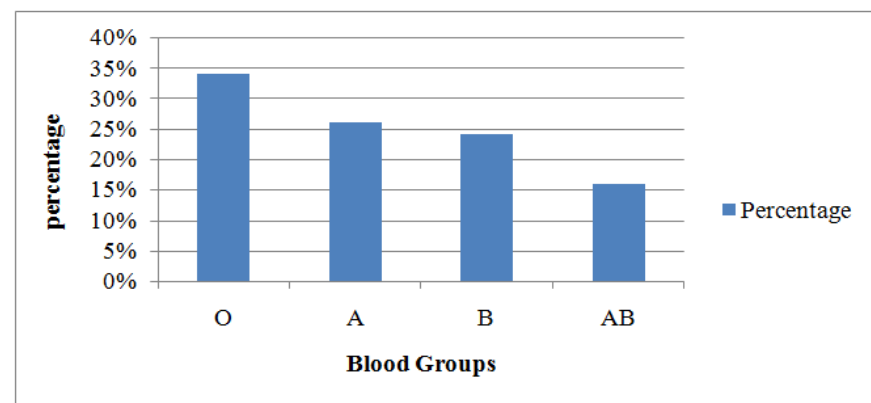

\section{Percentage of ABO Groups among the students}

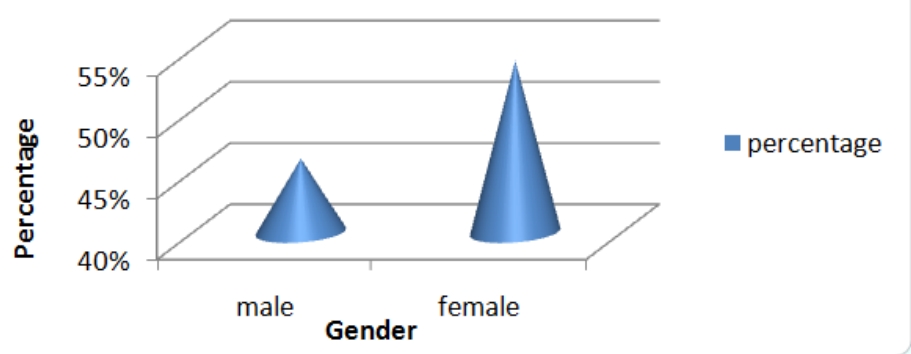

\section{Gender Percentage among study group}

\begin{tabular}{|c|c|c|}
\hline \multicolumn{2}{|c|}{ Table - 1. Distribution of clotting time on various blood groups. } \\
\hline BLOOD GROUP & $<6$ mins $(\%)$ & $>6 \operatorname{mins}(\%)$ \\
\hline $\mathrm{O}(34)$ & $24(67.6 \%)$ & $10(32.4 \%)$ \\
\hline $\mathrm{A}(26)$ & $15(57.7 \%)$ & $11(42.3 \%)$ \\
\hline $\mathrm{B}(24)$ & $13(54.2 \%)$ & $11(45.8 \%)$ \\
\hline $\mathrm{AB}(16)$ & $10(62.5 \%)$ & $6(37.5 \%)$ \\
\hline
\end{tabular}

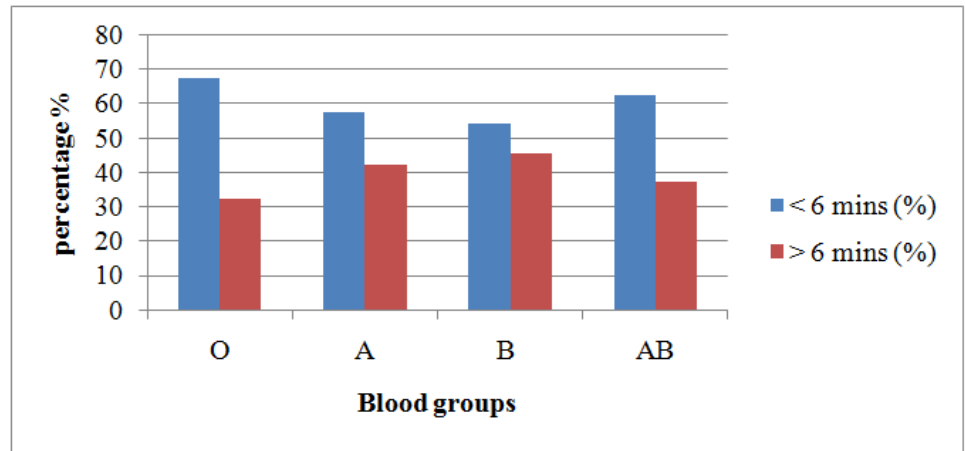

Graph showing Clotting time below and above 6 mins on various Blood groups

\begin{tabular}{|l|l|l|}
\hline \multicolumn{3}{|c|}{ Table - 2. Distribution of bleeding time on various blood groups. } \\
\hline BLOOD GROUP & $<4$ mins $(\%)$ & $>4$ mins $(\%)$ \\
\hline $\mathrm{O}(34)$ & $21(61.8 \%)$ & $13(38.2 \%)$ \\
\hline $\mathrm{A}(26)$ & $16(61.5 \%)$ & $10(38.5 \%)$ \\
\hline $\mathrm{B}(24)$ & $16(66.7 \%)$ & $8(33.3 \%)$ \\
\hline $\mathrm{AB}(10)$ & $9(56.3 \%)$ & $7(43.7 \%)$ \\
\hline
\end{tabular}




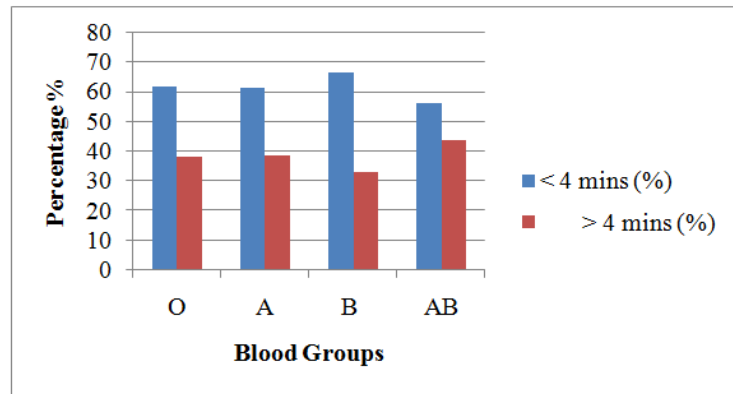

\section{Graph showing Bleeding time below and above 4 mins on various Blood groups}

\begin{tabular}{|l|l|l|}
\hline \multicolumn{3}{|c|}{ Table -3. Gender wise distribution of Clotting time. } \\
\hline GENDER & $<6$ mins $(\%)$ & $>6 \operatorname{mins}(\%)$ \\
\hline FEMALE(54) & $40(74.1 \%)$ & $14(25.9 \%)$ \\
\hline MALE(46) & $39(84.8 \%)$ & $7(15.2 \%)$ \\
\hline
\end{tabular}

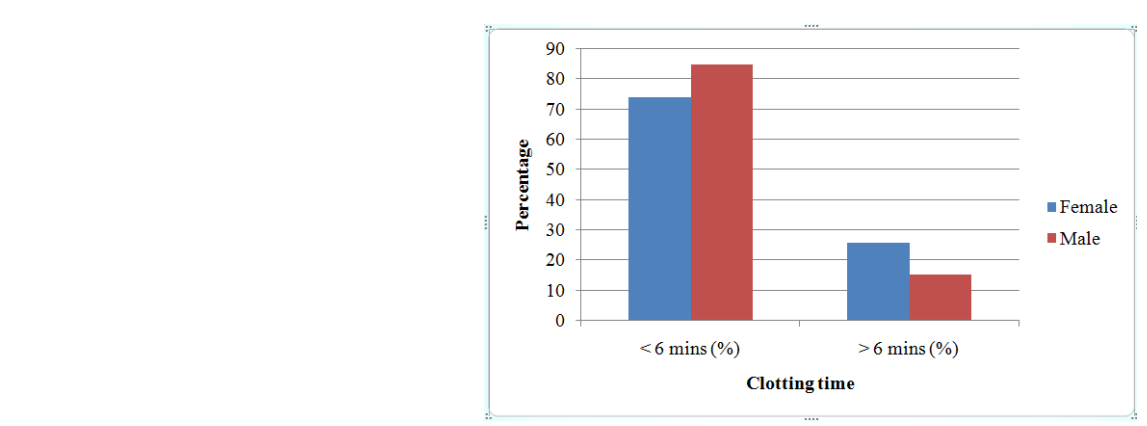

\section{Gender difference on Clotting time}

\begin{tabular}{|l|l|l|}
\hline \multicolumn{3}{|c|}{ Table -4. Gender wise distribution of Bleeding time. } \\
\hline GENDER & $<4$ mins $(\%)$ & $>4 \operatorname{mins}(\%)$ \\
\hline FEMALE(54) & $30(55.6 \%)$ & $24(44.4 \%)$ \\
\hline MALE(46) & $40(87 \%)$ & $6(13 \%)$ \\
\hline
\end{tabular}

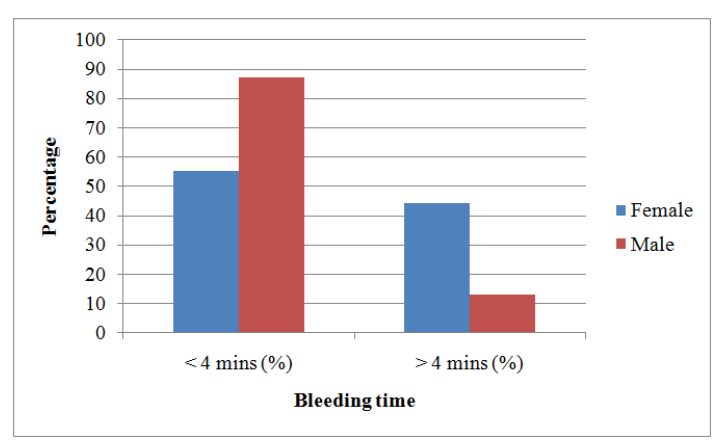

\section{Gender difference on Bleeding time}

It is observed that $45.8 \%$ ofB group students had clotting time more than 6 minutes compared to the $\mathrm{O}$ group (32.4\%), A group (42.3\%) and the $\mathrm{AB}$ group (37.5\%). There was statistical significance among the $\mathrm{ABO}$ groups with clotting time below 6 minutes and above 6 minutes showing $\mathrm{p}=0.002$.

Bleeding time was found to be more than 4 minutes in $\mathrm{AB}$ group (43.7\%) compared to group $\mathrm{O}$ (38.2\%), group $\mathrm{A}(38.5 \%)$ and group $\mathrm{B}(33.3 \%)$. Again there was statistical significance among the $\mathrm{ABO}$ groups with bleeding time below 4 minutes and above 4 minutes showing $\mathrm{p}=0.000$.

The difference in gender among Clotting time showed that $25.9 \%$ of female students had clotting time more than 6 minutes as compared to $15.2 \%$ in males. There was also similar difference in the bleeding time, where $44.4 \%$ of the female students had more than 4 minutes of bleeding time compared to $13 \%$ in male students. The student " $\mathrm{t}$ " test for bleeding time among male and female individuals showed a statistically significant value of $p=0.01$ and for the clotting time the $P$ value was $p=0.000$, which was also statistically significant. 


\section{Discussion:}

Several studies have been done so far to correlate the association between blood groups and the Bleeding and Clotting time. According to the review article written by Massimo Franchini et al, when compared to the type $\mathrm{O}$ group, the non $\mathrm{O}$ group individuals can have an increased risk of thrombosis due to the higher levels of vWF(13).He also states that, the ABO group can affect the vWF catabolism, meaning that the plasma vWF levels may dependupon blood group of the individual. This concept was accepted by other studies done by Jenkin's PO et al (14), who stated that vWF is $25 \%$ more in non $\mathrm{O}$ group individuals compared to group $\mathrm{O}$ individuals. This means that the clotting time and the bleeding time will be elevated among the $\mathrm{O}$ group individuals compared to the other groups. But, as per the study done by Mahapatra et al (15), clotting time was prolonged in the group Bindividuals and bleeding time was prolonged in the AB group compared to other groups. Out study also proved the same findings where the bleeding time was comparatively increased among the B group and the clotting time was increased in the individuals among AB group. But in the study done by Mahapatra et al, there was no difference in the bleeding time and clotting time among the males and females. In our study, $25.9 \%$ of female individuals had clotting time above 6 minutes compared to only $15.2 \%$ in the males. Likewise, $44.4 \%$ females had bleeding time more than 4 minutes compared to the $13 \%$ in the males. This finding goes along with the study done by Roy B et al (17), who had prolonged clotting and bleeding time among females compared to males. This fact that the female individuals having comparatively increased bleeding time and clotting time can be due to the presence of estrogens, which as per Ercan M et al (16), decrease the level of fibrinogen in the plasma and increase the clotting time.

\section{Conclusion:}

So far, it is said that the non $\mathrm{O}$ groups are more prone for thrombotic risk compared to $\mathrm{O}$ group, but our study suggests that, in the given study population clotting time was prolonged in the B group individuals and the bleeding time was prolonged in the AB group individuals compared to other groups. This leaves us to think the possibility of the thrombotic risk in $\mathrm{O}$ group individuals also. Moreover females had prolonged bleeding and clotting time compared to males.A larger study group has to be involved for further study and also the plasma von Willebrand factor levels should be estimated to rule out any possible reason for the different levels of clotting and bleeding time among the ABO groups. This will help us to identify the risk group and take necessary precautions as early as possible.

\section{References:}

[1] Watkins WM Biochemistry and genetics of ABO, Lewis and P blood group systems. Adv Hum Genet 1980;10:1-36

[2] Akhtar MN, Tayyib A, Tasneem T, Butt AR. ABO blood group in patients with peptic ulcer disease: Association with secretor status.Ann King Edward Med Coll 2003; 9: 238-40.

[3] Qureshi MA, Bhatti R. Frequency of ABO blood groups among the diabetes mellitus type 2 patients. J Coll Physicians Surg Pak $2003 ; 13: 453-5$.

[4] Ziegler T, Jacobsohn N, Fünfstück R. Correlation between blood group phenotype and virulence properties of Escherichia coli in patients with chronic urinary tract infection Int J Antimicrob Agents. 2004; 24 Suppl 1:S70-5.

[5] Mourant AE. Blood relations: Blood groups and anthropology. Oxford: Oxford University Press.1983, pp 1-146.

[6] Favaloro EJ, Soltani S, McDonald J, Grezchnik E, Easton L, Favaloro JW. Reassessment of ABO blood group, sex, and age on laboratory parameters used to diagnose von Willebrand disorder: potential influence on the diagnosis vs the potential association with risk of thrombosis Am J Clin Pathol. 2005; 124(6):910-7.

[7] Ruggeri ZM, Zimmerman TS: The complex multimeric composition of factor VIII/vWF. Blood 1981, 57:1140-1143

[8] Sadler JE: von Willebrand factor. Ann Rev Biochem 1998,67:395-424.

[9] Ruggeri ZM: Structure of von Willebrand factor and its functionin platelet adhesion and thrombus formation. Best Prac sssResClinical Haematol 2001, 14:257-259.

[10] Gill JC, Endres-Brooks J, Bauer PJ, Marks WJ Jr, Montgomery RR. The effect of ABO blood group on the diagnosis of von Willebrand disease, Blood. 1987; 69(6):1691-5.

[11] Daniel, M., M.C. Jaberoo, R.E. Stead, V.M. Reddy and A.A. Moir, 2006. Is admission for epistaxismore common in Caucasian than in Asian people? Preliminary study. Clin. Otolaryngol., 31: 386-389.

[13] Massimo Franchini*1, Franco Capra2, Giovanni Targher3, Martina Montagnana4 and Giuseppe Lippi4Relationship between ABO blood group and von Willebrand factor levels: from biology to clinical implications.Thrombosis journal 2007, 5:14.

[14] Jenkins PV, O’Donnell JS. ABO blood group determines plasma von Willebrand factor levels: a biologic function after all? Transfusion. 2006; 46 (10): 1836-1844.

[15] Mahapatra B, Mishra N. Comparison of Bleeding Time and Clotting Time in Different Blood Groups, American Journal of Infectious Diseases 2009; 5 (2): 113-115.

[16] Ercan M, Yegin E, Akdeniz H, Irmak H, Bayiroglu F, Tuncer I. Effect of Estrogen on Fibrinogen Clotting Time in Rabbits. Tr. J. of Veterinary and Animal Sciences 1998;22:137-40.

[17] Roy B1, Banerjee I2, Sathian B3, Mondal M4, Saha CG5 Blood Group Distribution and Its Relationship with Bleeding Time and Clotting Time: A Medical School Based Observational Study.Nepal Journal of Epidemiology 2011; 1(4): 135 -140

Books:

[12] Ghai, C.L., 1999. A Textbook of Practical Physiology. 5th Edn., Jaypee Brothers, New Delhi,Haematology, pp: 84-101. 